\title{
PENGARUH SERVICESCAPE TERHADAP KEPUASAN PENGGUNA JASA (Studi Kasus Pada Kantor Imigrasi Kelas I Malang)
}

\author{
Vivin Muarifah \\ Department of Management FEB UMM \\ E-mail : vivinmuarifah@gmail.com
}

\begin{abstract}
This study aimed to investigated the impact of servicescape on services user satisfaction at malang's immigration office class 1 . The analytical method used is multiple regression analysis. This research was conducted by distributing questionaires to 100 respondents at malang's immigration office class 1 by using accidental sampling technique. Dimensions of servicescape that used in this study are ambient condition, spatial layout and functionality, signs, symbols, and artifacts, and social. Results of the analysis shows that dimensions servicescape have influence on services user satisfaction either simultaneously or partially
\end{abstract}

Keywords: servicescape, services user satisfaction

\section{PENDAHULUAN}

Dalam suatu perusahan jasa, menciptakan pengalaman yang berkesan bagi pengguna jasa yang datang adalah suatu tantangan tersendiri. Melihat sifat sebagian besar produk jasa itu adalah abstrak dan tidak berwujud, membuat setiap aspek yang ada di sekitar jasa inti perusahaan menjadi pertimbangan bagi pengguna jasa. Salah satu aspek tersebut adalah lingkungan tempat penyampaian jasa tersebut berada (Servicescape).

Servicescapes adalah istilah yang dikembangkan oleh Bitner pada tahun 1992. Istilah servicescape merujuk pada penampilan dari lingkungan physic buatan dan juga mencakup unsur-unsur lain lingkungan kerja yang membentuk respon atau perilaku karyawan.

\begin{abstract}
Aspek-aspek yang terdapat dalam lingkungan fisik meliputi kondisi ambient (temperatur udara, warna, noise, musik dan aroma wewangian), space/ function (layout, perlengkapan dan furnitur) dan dengan melihat apakah terdapat sign, symbol dan artifact yang dapat mengkomunikasikan maksud perusahaan secara implisit maupun eksplisit.

Sejumlah riset menunjukan bahwa design servicescape bisa mempengaruhi pengguna jasa, ekspektasi pengguna jasa, kepuasaan pengguna jasa, dan perilaku lainnya. Hasil penelitian yang dilaksanakan oleh Kearney, Coughlan, dan Kennedy menyimpulkan bahwa faktor servicescape yaitu layout dan ambience berpengaruh signifikan pada kepuasan konsumen. Hasil
\end{abstract}


penelitian dari Setiady, Sukriah, dan Rosita (2015) menunjukan bahwa servicescape memiliki pengaruh positif terhadap kepuasan pengunjung.

Seluruh kegiatan dan pelayanan yang dilakukan oleh perusahaan pada akhirnya akan berujung pada value yang akan diberikan oleh pengguna jasa mengenai kepuasan yang mereka rasakan. Kepuasan merupakan tingkat perasaan di mana seseorang menyatakan hasil perbandingan atas kinerja produk jasa yang diterima dengan yang diharapkan (Kotler, 2012). Sedangkan, Wilkie (1990) mendefinisikan kepuasan pengguna jasasebagai respon emosional pada penilaian terhadap pengalaman konsumsi suatu produk atau jasa.

Kantor Imigrasi Kelas I Malang merupakan salah satu unit pelaksana teknis keimigrasian yang berada di jajaran Kementrian Hukum dan HAM yang bertanggung jawab langsung kepada kantor Wilayah Kementrian Hukum dan HAM Jawa Timur. Peran Kantor Imigrasi sangat penting mengingat pelaksanaan dan pelayanan keimigrasian yang menyangkut Warga Negara Indonesia (WNI) dan Warga Negara Asing (WNA) harus melewati proses dan prosedur yang cukup banyak. Kantor Imigrasi tidak lepas dari kendala proses antrian pengguna jasa yang tidak teratur sehingga menyebabkan terjadinya desak desakan antar pengguna jasa dan kerap kali menimbulkan situasi yang tidak terkendali, dan banyaknya pengguna jasa yang tidak mengerti alur dan prosedur yang harus dilewati serta syarat yang harus dilengkapi membuat karyawan
Kantor Imigrasi merasa kewalahan.

Kendala lainnya yang terkait dengan layout kantor imigrasi adalah tidak tepatnya penempatan area parkir yang berada didalam kantor membuat pengguna jasa merasa kesulitan untuk memasukkan kendaraannya karena harus melewati para kerumunan pengguna jasa yang sedang antri ataupun menunggu nomer antrian. Selain itu, ketidak jelasan jadwal kerja kantor imigrasi adalah masalah yang seringkali menjadi bahasan utama pengguna jasa saat menyampaikan protesnya kepada karyawan kantor imigrasi.

Berdasarkan dari fenomena yang disebutkan di atas maka dapat diasumsikan bahwa kendala yang dihadapi oleh Kantor Imigrasi Malang disebabkan oleh servicescape yang belum di design dengan baik. Tingginya interaksi antar Kantor Imigrasi dengan pengguna jasa (Service User) setiap harinya menunjukkan bahwa permintaan akan jasa dari Kantor Imigrasi sangatlah besar. Peningkatan pelayanan jasa pun menjadi suatu keharusan yang harus dilakukan oleh Kantor Imigrasi karena jasa bersifat intagible maka pengguna jasa kerap kali mengandalkan physical evidance (lingkungan fisik) yang berupa servicescape untuk mengevaluasi sebuah jasa dan menilai kepuasannya selama dan setelah menggunakan.

Berdasarkan latar belakang yang telah diuraikan, maka dapat dirumuskan rumusan masalah sebagai berikut: 1. Bagaimanakah servicescape di Kantor Imigrasi Klas I Malang? 2. Apakah servicescapes (ambient condition, tata letak dan fungsinya, tanda, simbol dan artifak, 
serta sosial) memiliki pengaruh terhadap kepuasan pengguna jasa di kantor imigrasi Klas I Malang? 3. Variabel manakah yang paling berpengaruh terhadap kepuasan pengguna jasa? 4. Bagaimanakah servicescape Kantor Imigrasi Klas I Malang menurut keputusan operasional?

Batasan masalah pada penelitian ini hanya terbatas pada pengguna jasa pembuatan passport. Tujuan dari penelitian ini adalah untuk mengetahui pengaruh servicescape terhadap kepuasan pengguna jasa Kantor Imigrasi Klas I Malang.

\section{TINJAUAN PUSTAKA}

Penelitian pada tahun 2014 yang dilakukan oleh Michael Tumbelaka dan Sjendy Loindong pada Bank BRI branch Manado dengan menggunakan alat analisis regresi berganda dan jumlah sampel sebanyak 125 orang. Menyimpulkan bahwa servicescape berpengaruh signifikan pada kepuasan nasabah.

Penelitian lain juga dilakukan oleh Lee pada tahun 2011 dengan jumlah sampelsebanyak 170 orang dan dengan menggunakan alat analisis regresi menunjukan bahwa servicescape berpengaruh pada kepuasan, persepsi kualitas dan pendekatan perilaku pengguna jasa.

Servicescape menurut Bitner adalah pengaturan lingkungan fisik yang diciptakan supaya mendukung layanan yang diberikan oleh suatu organisasi. Istilah servicescape merujuk pada gaya \&penampilan dari lingkungan fisik dan juga mencangkup unsur-unsur lain dari lingkungan jasa yang membentuk pengalaman pengguna jasa. McComish dan Quester (2005) berpendapat bahwa servicescape adalah suatu kesatuan lingkungan physical dari sebuah perusahaan jasa yang memiliki pengaruh kepada pengalaman pengguna jasa. Designe archictecture dan design element yang terkait merupakan komponen penting dari suatu servicescape. servicescape dan selanjutnya pada respon internal dan respon eksternal

Bitner menyatakan bahwa ada 3 dimensi servicescape yaitu, Ambient condition (kondisi sekitar), tata letak dan fungsionalitas, dan tanda, simbol, artifak. Sedangkan Hightower membagi servicescape menjadi dimensi ambient, design, dan sosial. Berdasarkan elaborasi di atas, peneliti merumuskan empat dimensi servicescape yang akan digunakan untuk meneliti Kantor Imigrasi Klas I Malang. Dimensidimensi tersebut adalah (1) ambient condition (2) spatial layout and functionality (3) sign, symbol, and artifact (4) sosial. Keempat dimensi ini menurut Bitner dianggap mempengaruhi kepuasan pengguna jasa. Hal ini juga dikuatkan oleh pernyataan Wakefield dan Blodgett (2011) yang menyatakan bahwa semakin lama seseorang berada di suatu lingkungan fasilitas maka semakin besar pula kualitas yang dirasakan dari servicescape. Sehingga servicescape memiliki important role dalam menentukan kepuasan jasa.

Wilkie (1994) mengartikan kepuasan pengguna jasa sebagai emotional response pada penilaian terhadap pengalaman konsumsi suatu product atau jasa. dilain sisi, Engel, et al (1995) menyatakan bahwa kepuasan pengguna jasa merupakan evaluasi setelah pembelian di mana 
alternatif yang dipilih sekurangkurangnya sama atau melebihi harapan pengguna jasa, sedangkan ketidakpuasan timbul apabila outcome tidak memenuhi harapan pengguna jasa. Hubungan antar masing-masing dimensi servicescape terhadap keputusan pengguna jasa dapat dilihat daam kerangka pikir dibawah ini:

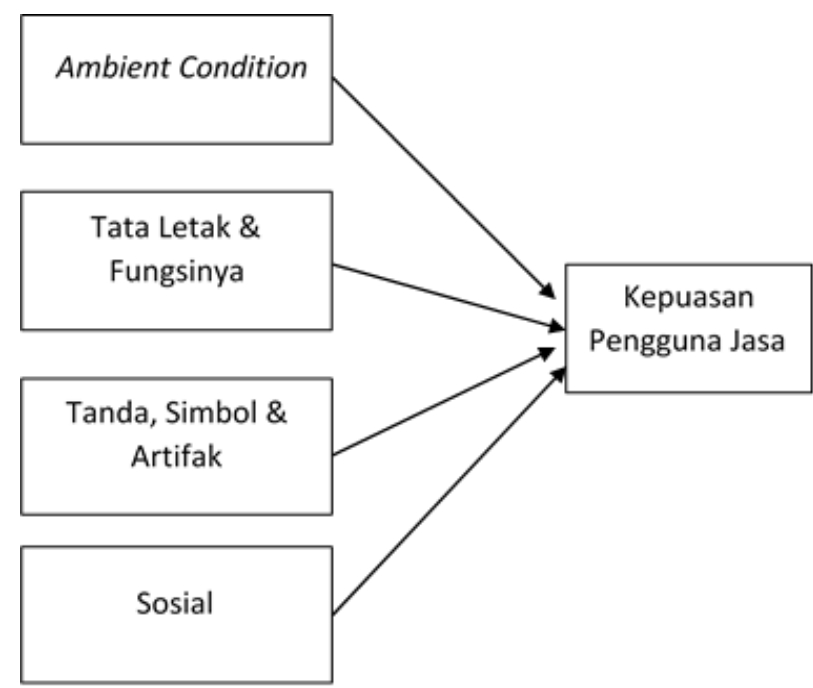

Gambar 1. Kerangka Pikir Penelitian

Dari kerangka pikir di atas dijelaskan bahwa terdapat tiga dimensi pembentuk servicescapes yaitu pertama, ambient condition yang merujuk pada karakteristik lingkungan yang berkaitan dengan panca indera. Sub dimensi dari ambient condition meliputi musik, warna, pencahayaan, suhu udara, dan kebisingan. Kedua, Tata Letak dan fungsinya mengacu pada cara di mana objek seperti mesin, peralatan, dan perabot diatur dalam lingkungan jasa.

Ketiga, Tanda, simbol dan artifak berfungsi untuk mengkomunikasikan pesan simbolik agar menciptakan kesan estetika secara keseluruhan. Keempat, Sosial mengacu pada keramahan karyawan serta kualitas pelayanan yang diberikan. Seorang pengguna jasa dikatakan puas apabila terdapat kesamaan antara harapan sebelum menggunakan jasa dengan pelayanan yang diterima selama dan setelah menggunakan jasa.

Berdasarkan Perumusan masalah yang telah dijelaskan, maka diajukan hipotesis sebagai berikut: 1 . Servicescape berpengaruh terhadap kepuasan pengguna jasa. 2. Tata letak dan fungsionalitas merupakan dimensi paling berpengaruh terhadap kepuasan pengguna jasa.

\section{METODE PENELITIAN}

Jenis penelitian yang digunakan dalam penelitian ini adalah penelitian kualitatif dan kuantitatif. Penelitian kuantitatif adalah penelitian untuk mengetahui tolak ukur relasi antara variabel independen dengan variabel dependen. Sementara penelitian kualititatif adalah penelitian yang bersifat deskriptif dan cenderung menggunakan analisis. 
Populasi dalam penelitian ini adalah seluruh pemohon pembuatan passport. Kapasitas pembuatan passport di kantor Imigrasi Malang adalah sebesar 175 pemohon perhari, di mana penelitian akan dilakukan selama dua minggu (10 hari kerja). Maka, jumlah populasi dalam penelitian ini adalah 1750 pemohon.

Pengambilan sampel pada penelitian ini menggunakan teknik accidental sampling dan untuk penentuan jumlah sampel yang diambil menggunakan rumus slovin dengan batas toleransi kesalahan $10 \%$. Dari perhitungan tersebut didapatkan hasil sebesar 95 yang dibulatkan menjadi 100 responden.

Dalam penelitian ini data yang digunakan adalah data primer. Data primer adalah data yang diolah sendiri oleh suatu organisasi atau perorangan langsung dari obyeknya. Data primer dari penelitian ini diperoleh dari kuesioner yang diisi oleh pengguna jasa pembuatan passport Kantor Imigrasi Malang.

Teknik pengukuran data yang digunakan adalah skala likert 1-5 dan alat analisis yang digunakan adalah regresi linier berganda, asumsi klasik, uji F dan T.

\section{HASIL DAN PEMBAHASAN}

Untuk mengetahui hubungan antar variabel diperlukan pengujian regresi linier berganda, uji asumsi klasik untuk mengetahui keberartian hubungan antara variabel terikat dan variabel bebas. Tahap pertama dengan menggunakan uji asumsi klasik yang terdiri dari uji normalitas untuk menguji apakah pada model regresi variabel terikat, variabel bebas atau keduanya mempunyai distribusi normal atau tidak. Yang diuji menggunakan SPSS versi 23.00 dengan hasil sebagai berikut:

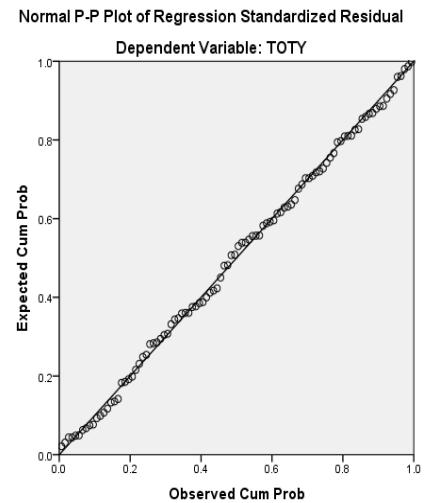

Gambar 2. Hasil Uji Normalitas

Dilihat dari gambar 2 maka dapat disimpulkan bahwa grafik histogram memberikan pola distribusi yang normal karena data berpencar di sekitar garis diagonal dan mengikuti arah garis diagonal, maka model regresi pada penelitian ini dapat dinyatakan memenuhi asumsi normalitas.

Tahap selanjutnya dengan uji heteroskedastisitas yang digunakan untuk mengetahui apakah model regresi terjadi perbedaan varian dari satu pengamatan ke pengamatan yang lain yang dijelaskan dalam gambar 3:

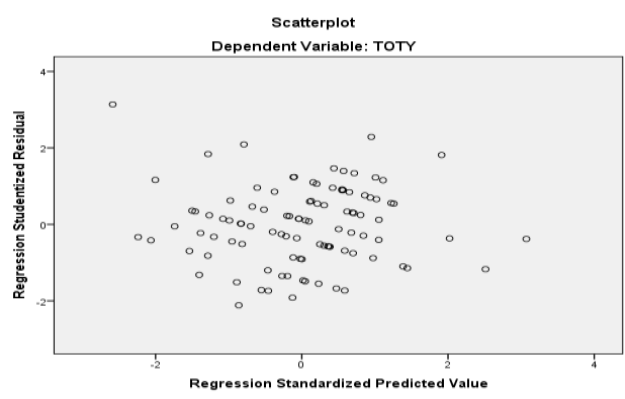

Gambar 3. Hasil Uji Heteroskedasititas

Gambar 3. menunjukkan grafik scatterplots terlihat bahwa titik-titik 
menyebar secara acak serta tersebar baik diatas maupun dibawah angka 0 pada sumbu Y. Maka dapat disimpulkan tidak terjadi heteroskedastisitas pada model regresi, model regresi dikatakan layak dipakai untuk mempediksi kepuasan pengguna jasa.
Tahap selanjutnya yakni uji autokorelasi digunakan untuk menguji apakah dalam model regresi linear ada hubungan antara kesalahan pengganggu pada periode $\mathrm{t}$ dengan kesalahan penggangggu pada periode t-1. Hasil uji autokorelasi dapat dilihat ditabel dibawah ini:

Tabel 1. Uji Autokorelasi

\begin{tabular}{cccccc}
\hline Model & $\mathrm{R}$ & R Square & $\begin{array}{c}\text { Adjusted R } \\
\text { Square }\end{array}$ & $\begin{array}{c}\text { Std. Error of } \\
\text { The Estimate }\end{array}$ & $\begin{array}{c}\text { Durbin- } \\
\text { Watson }\end{array}$ \\
\hline 1 & $.449^{\mathrm{a}}$ & .202 & .168 & 1.945 & 1.716 \\
\hline
\end{tabular}

Tabel 1 menunjukkan hasil uji autokorelasi dengan DW test dengan nilai sebesar 1,718. Oleh karena nilai DW 1,718 lebih kecil dari batas atas (du) 1,76 dan kurang dari 4 - 1,76 (4du), maka dapat disimpulkan bahwa Ho tidak bisa ditolak, ini juga berarti tidak ada autokorelasi positif atau negatif atau dapat disimpulkan tidak terdapat autokorelasi.

Selanjutnya dilakukan Uji Multikolinearitas bertujuan untuk verify dalam model regresi ditemukan adanya korelasi antar variabel-variabel bebas, yang hasilnya akan ditunjukkan Tabel 2.

Tabel 2. Hasil Uji Multikolinieritas

\begin{tabular}{|c|c|c|c|c|c|c|c|}
\hline \multirow[t]{2}{*}{ Model } & \multicolumn{2}{|c|}{$\begin{array}{c}\text { Unstandarized } \\
\text { Coefficients } \\
\text { Persentase } \\
\end{array}$} & \multirow{2}{*}{$\begin{array}{c}\begin{array}{c}\text { Standardized } \\
\text { Coefficints }\end{array} \\
\text { Beta }\end{array}$} & \multirow[t]{2}{*}{$\mathrm{T}$} & \multirow[t]{2}{*}{ Sig. } & \multicolumn{2}{|c|}{$\begin{array}{c}\text { Collinearity } \\
\text { Statistics }\end{array}$} \\
\hline & B & Std. Error & & & & Tolerance & VIF \\
\hline (Constant) & 1.841 & 1.713 & & 1.075 & .285 & & \\
\hline TOTX1 & .017 & .073 & .023 & .233 & .816 & .889 & 1.124 \\
\hline TOTX2 & .207 & .079 & .248 & 2.620 & .010 & .936 & 1.068 \\
\hline TOTX3 & .175 & .092 & .191 & 1.907 & .060 & .836 & 1.197 \\
\hline TOTX4 & .195 & .084 & .217 & 2.314 & .023 & .953 & 1.047 \\
\hline
\end{tabular}

Tabel 2 menunjukkan tidak ada variabel yang memiliki nilai tolerance tidak lebih dari 0,10 yang berarti tidak ada correlation antar variabel bebas yang nilainya lebih dari $95 \%$ serta tidak ada satupun variabel bebas yang memiliki nilai
VIF lebih dari 10. Dapat disimpulkan bahwa tidak ada multikolonieritas antar variabel bebas dalam model regresi. Hasil analisis regresi linier berganda menggunakan 4 variabel bebas dan1variabel terikat dengan disajikan dalam tabel berikut: 
Tabel 3. Karakteristik Responden Berdasarkan Status Responden

\begin{tabular}{cccccc}
\hline \multirow{2}{*}{ Model } & \multicolumn{2}{c}{$\begin{array}{c}\text { Unstandarized Coefficients } \\
\text { Persentase }\end{array}$} & $\begin{array}{c}\text { Standardized } \\
\text { Coefficints }\end{array}$ & \multirow{2}{*}{ T } & Sig. \\
\cline { 2 - 4 } & $\mathrm{B}$ & Std. Error & Beta & & \\
\hline (Constant) & 1.961 & 1.626 & & 1.206 & .231 \\
TOTX2 & .208 & .079 & .249 & 2.642 & .010 \\
TOTX3 & .181 & .087 & .198 & 2.073 & .041 \\
TOTX4 & .197 & .084 & .219 & 2.352 & .021 \\
\hline
\end{tabular}

Hasil dari Tabel 3 kemudian dapat ditarik ke persamaan regresi berganda sebagai berikut: $\mathrm{Y}=1,961$ $+0,208 X_{2}+0,181 X_{3}+0,197 X_{4}$

Berdasarkan persamaan di atas, maka dapat ditarik kesimpulan bahwa jika semua variabel bebas memiliki nilai tetap (0) maka nilai variabel terikat (Y) sebesar 1,961. Sehingga dapat disimpulkan bahwa tanpa ada servicescape pun, pengguna jasa akan tetap memiliki kepuasan dalam menggunakan jasa atau pelayanan kantor imigrasi Klas 1 Malang. Nilai koefisien regresi tata letak dan fungsionalitas untuk variabel (X2) sebesar 0,208. Jika variabel tata letak dan fungsionalitas (X1) meningkat dengan asumsi variabel ambient condition (X1), tanda, simbol, dan artifak (X3), sosial (X4) tetap (0), maka kepuasan pengguna jasa (Y) juga akan meningkat.

Nilai koefisien regresi tanda, simbol, dan artifak untuk variabel (X3) sebesar 0,181. Jika variabel tanda, simbol, dan artifak (X3) meningkat dengan asumsi variabel ambient condition (X1), tata letak dan fungsionalitas (X2), sosial (X4) tetap (0), maka kepuasan pengguna jasa (Y) juga akan meningkat. Nilai koefisien sosial untuk variabel (X4) sebesar 0,197. Jika variabel tanda, simbol, dan artifak (X4) satuan dengan asumsi variabel ambient condition (X1), tata letak dan fungsionalitas (X2), tanda, simbol, artifak (X3) tetap (0), maka kepuasan pengguna jasa (Y) juga akan meningkat. Untuk mengetahui signifikansi hipotesa dalam penelitian ini maka perlu dilakukan Uji F sebagai berikut:

Tabel 4. Uji F

\begin{tabular}{lccccc}
\hline \multicolumn{1}{c}{ Model } & $\begin{array}{c}\text { Sum of } \\
\text { Squares }\end{array}$ & Dif & Mean Square & F & Sig. \\
\hline Regression & 90.788 & 4 & 22.692 & 5.997 & .000 \\
Residual & 359.472 & 96 & 3.784 & & \\
$\quad$ Total & 460.240 & 99 & & & \\
\hline
\end{tabular}


Berdasarkan tabel 4 nilai $\mathrm{F}$ hitung sebesar 5.997 Sedangkan F tabel $(\alpha=0.05 ; \mathrm{db}$ regresi $=4: \mathrm{df}$ residual $=95)$ adalah sebesar 2.46 . Karena $\mathrm{F}$ hitung $>\mathrm{F}$ tabel yaitu $5,997>2.46$ atau nilai Sig. F $(0,000)$ $<\alpha=0.05$ maka model analisis regresi adalah signifikan. Hal ini dapat disimpulkan bahwa kepuasan pengguna jasa(Y) dipengaruhi secara bersama-sama oleh variabel bebas ambient condition (X1), tata letak dan fungsionalitas (X2), tanda, simbol, dan artifak (X3), dan sosial (X4).

Selanjutnya dilakukan uji t pada dasarnya menunjukkan seberapa jauh pengaruh satu variabel bebas secara individual dalam menerangkan variasi variabelterikat secara individual yang ditampilkan dalam tabel berikut:

Tabel 5. Hasil Uji T

\begin{tabular}{cccc}
\hline Variabel & $\mathrm{T}_{\text {hitung }}$ & $\mathrm{T}_{\text {tabel }}$ & Keterangan \\
\hline $\begin{array}{c}\text { Ambient Condition } \\
\text { Tata letak dan }\end{array}$ & 0,233 & 0,1650 & $\begin{array}{c}\text { Tidak Signifikan } \\
\text { Signifikan }\end{array}$ \\
$\begin{array}{c}\text { fungsionalitas } \\
\text { Tanda, Simbol dan artifak }\end{array}$ & 2,620 & 0,1650 & \\
Sosial & 1,907 & 0,1650 & Signifikan \\
& 2,314 & 0,1650 & Signifikan \\
\hline
\end{tabular}

Dari uraian tabel 5 maka dapat diketahui bahwa hasil analisis antara $\mathrm{X} 2$ (tata letak dan fungsionalitas) dengan Y (kepuasan pengguna jasa) menunjukkan $\mathrm{t}$ hitung $=2,620$. Sedangkan $\mathrm{t}$ tabel $(\alpha=0.05 ; \mathrm{db}$ residual $=100$ ) adalah sebesar 1,984 . Karena $\mathrm{t}$ hitung $>\mathrm{t}$ tabel yaitu 2,620 $>1,984$ atau sig. $\mathrm{t}(0,005)<\alpha=0.05$ maka dapat diartikan bahwa pengaruh X2 (tata letak dan fungsionalitas) signifikan terhadap kepuasan pengguna jasa.

Dalam penelitian ini servicescape pada kantor imigrasi Klas 1 malang terbagi menjadi 4 dimensi. Pertama, ambient condition Kedua, Tata letak dan Ketiga, Tanda, Simbol, dan Artifak yang berhubungan dengan kemudahan memahami gambar arus prosedur, kelengkapan informasi pada brosur, dan hiasan interior yang menarik. Keempat, Sosial yang berhubungan dengan keramahan karyawan, jumlah karyawan yang mencukupi, dan kesenangan karyawan dalam membantu pengguna jasa. Hasil penelitian ini menyatakan bahwa servicescape (lingkungan layanan) serta dimensi - dimensi yang ada di dalamnya seperti kondisi ambient condition, tata letak dan fungsionalitas, tanda, simbol, artifak, dan karyawan memiliki pengaruh terhadap kepuasan pengguna jasa.

Hasil penelitian ini juga menunjukan bahwa tata letak dan fungsionalitas memiliki pengaruh terhadap kepuasan pengguna jasa paling besar dibandingkan dengan sub variabel lainnya. Sehingga dapat dikatakan hipotesis ke-2 yang menyatakan dimensi tata letak dan fungsionalitas adalah yang paling berpengaruh. Dalam 10 Keputusan Operasional, servicescape termasuk didalam Design Tata Letak. Tata letak merupakan suatu keputusan 
penting untuk menentukan efisiensi operasi secara jangka panjang. Dalam servicescape Kantor Imigrasi Klas I Malang hal yang harus diperhatikan untuk menentukan design tata letak adalah standarisasi bangunan untuk kantor imigrasi.

Berikut tata letak kantor yang harus diperhatikan agar Kantor Imigrasi memiliki servicescape yang baik: (1) Ruang pelayanan yang nyaman dan menyenangkan, (2) Suasana yang dapat mendukung pelaksanaan tugas dan pelayanan, (3) Penataan ruang sesuai dengan fungsi utama, (4)Kontrol terhadap temperatur, sirkulasi udara, dan penerangan, (5) Ruang direncanakan dengan pendekatan fisik pengguna layanan.

\section{SIMPULAN}

Hasil penelitian dapat disimpulan bahwaServicescape berpengaruh pada kepuasan pengguna jasa pembuatan passport baik secara parsial maupun simultan dan dimensi yang paling berpengaruh terhadap kepuasan pengguna jasa adalah dimensi tata letak dan fungsionalitas.

Pihak kantor imigrasi disarankan hendaknya untuk memperhatikan tata letak masing masing ruang pelayanan dan fasilitas penunjang yang dimiliki yang mencangkup area parkir, ruang tunggu, ruang pengecekan berkas, dan ruang tunggu interview dan jika mungkin untuk memperbanyak jumlah kursi untuk pengguna jasa dan menyediakan ruangan yang lebih luas untuk layanan pengecekan berkas.

\section{DAFTAR PUSTAKA}

Arikunto, S. 2010. Prosedur Penelitian : Suatu Pendekatan Praktik, Rineka Cipta

Bitner, Mary Jo. 1992, Servicescape: The Impact of Physical surroundings on Customers and Employees, Journal Marketing, Vol. 56

CM Hall, Mitchell, R. 2008, Wine Marketing: A Practical Approach Oxford Butterworth Heinemann.

Engel, et al (1995), Consumer Behavior, Forth Worth, Dryden Press

Ghozali, Imam. 2013. Aplikasi Analisis Multivariate dengan Program SPSS, BP UNDIP, Semarang.

Heizer, J. Render, B. 2006. Manajemen Operasi Edisi Tujuh, Salemba Empat, Jakarta

Kearney, T. Kennedy, A and Coughlan, J. 2012, An Exploration of the Effects of the Servicescape on Customer and Employee Responses in a Grocery Retail Context

Kotler, P. and Keller, K.L. 2006, Manajemen Pemasaran, Erlangga, Jakarta

Lovelock, 2010. Pemasaran JasaPerspektif Indonesia, Erlangga, Jakarta

Matilla, Wirtz. 2001, Congruency of Scent and Music as a Driver of in-store Evaluations and Behaviour, Journal of Retailing

McComish, M. and P.G. Quester (2005), Consumer Affective Response to the Retailscape: A Spatial and Temporal Perspective, ANZMAC 2005 
Conference: Retailing, Distribution Channel and Supply Chain Management, The University of Adelaide

Raza, Impact Of Servicescape On Customer Satisfaction, International Journal of Economic Business and Social Science, Vol 1

Sara O, Marberry and Laurie. Z, The Power of Color-Creating Healthy Interior Spaces, New York

Setiady, Sukriah, dan Rosita. 2015, Pengaruh Servicescape Terhadap Kepuasan Pengunjung di Floating Market Lembang, Jurnal Manajemen Resort \&Leisure, Vol 12

Sugiyono, 2015. Statistik Nonparametris Untuk Penelitian, Alfabeta
Tjiptono, Fandy. 2014. Pemasaran Jasa, Penerbit Andy, Yogyakarta Wakefield, K.L. and Blodgett, J.G (1996), The Effect of the Servicescape On Customer Behavioural Intentions in Leisure Service Setting. Journal Of Service Marketing.

Westbrook, R.A. and M.D. Reilly (1990), Value-perceipt Disparity: An Alternative to the Disconfirmation of Expectation Theory of Consumer Satisfaction, Assosiation of Consumer Research

Wilkie, W.L, 1994, Consumer Behaviour, New York:John Wiley \& Sons

Yazid, 2001. Pemasaran Jasa Konsep dan Implementasi, Ekonisia, Yogyakarta 